\title{
Fish consumption and cardiovascular response during mental stress
}

\author{
Kenta Matsumura ${ }^{1,6^{*}}$, Takehiro Yamakoshi ${ }^{2}$, Hiroko Noguchi ${ }^{1,3,6}$, Peter Rolfe ${ }^{4}$ and Yutaka Matsuoka $a^{1,5,6,7}$
}

\begin{abstract}
Background: Frequent fish consumption is related to a lower risk of coronary heart disease. However, the physiological mechanisms underlying this cardioprotective effect are as yet unknown. We therefore examined certain cardiovascular physiological variables of fish eaters during rest, whilst conducting mental arithmetic, and during recovery.

Findings: The participants were 12 fish eaters (eating baked fish more than 3-4 times/week) and 13 controls (eating fish less than 1-2 times/week). Analysis of the collected data revealed that heart rate, blood pressure, and pulse wave velocity were significantly lower and pre-ejection period and baroreflex sensitivity were significantly higher in the fish eaters than in the controls during both rest and mental arithmetic, and that systolic and mean blood pressure recovery from mental arithmetic were faster in the fish eaters than in the controls.

Conclusions: These findings suggest a possible physiological mechanism that may explain why frequent fish consumption reduces coronary heart disease risk.
\end{abstract}

Keywords: Fish consumption, Hemodynamics, Impedance cardiography, Arterial stiffness, Coronary heart diseases, Omega-3 fatty acids

\section{Findings}

\section{Introduction}

Accumulating evidence from human meta-analysis and large-scale epidemiological studies has shown that frequent fish consumption protects against coronary heart disease (CHD) [1-4]. Recent studies on cardiovascular function and hemodynamics have attempted to elucidate the possible mechanisms underlying this cardioprotective effect. For example, frequent fish consumption in the elderly is associated with lower blood pressure, heart rate, and total peripheral resistance [5]. However, little is known about the effect of frequent fish consumption on cardiovascular behavior during acute mental stress. This is somewhat surprising considering that exaggerated cardiovascular reactivity to [6-9], and/or slow recovery from acute laboratory mental stress [10], that show striking

\footnotetext{
* Correspondence: kenta16moon@se.kanazawa-u.ac.jp

${ }^{1}$ Department of Adult Mental Health, National Institute of Mental Health, National Center of Neurology and Psychiatry, 4-1-1 Ogawa-Higashi, Kodaira, Tokyo 187-8553, Japan

${ }^{6}$ CREST, Japan Science and Technology Agency, 3256 Midori-cho, Tachikawa, Tokyo 190-0014, Japan

Full list of author information is available at the end of the article
}

individual differences from one's early years $[11,12]$, have been implicated in the pathogenesis of CHD.

As for the relationship between fish consumption and stress reactivity, to our knowledge, there are four related human studies [13-16]. These are studies that examined the effect of the supplementation of the omega-3 fatty acid such as docosahexaenoic acid (DHA) and eicosapentaenoic acid (EPA) on cardiovascular reactivity during stress. DHA and EPA is known to be almost exclusively contained in fish oil, and considered to be the main substance that protects against coronary heart disease [17]. Among these four studies, two [15,16] were intact randomized control trials (RCT), but the result was contrary; that is, one [15] was positive, the other [16] was negative. Although there were many differences between these two studies such as the stress task used and the dose of omega-3 fatty acids, one highly plausible explanation as to this discrepancy is that the duration of supplementation was too short to consistently affect stress reactivity and/or recovery. According to a metaanalysis study that sums up 30 RCTs [18], at least twelve weeks of supplementation is necessary to stably lower resting heart rate, but the duration of the above

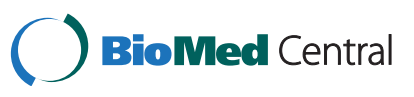


mentioned contradictory RCTs were 3 weeks and 4 weeks, respectively.

In the present study, therefore, we examined cardiovascular behavior of young fish-eaters at rest, during acute mental stress, and during recovery. Fish-eaters would have a diet that contains a high concentration of omega-3 fatty acid long enough to affect cardiovascular measures. To carry out this study, we recruited one group of individuals who had the habit of regularly eating fish and a second group who did not. The two groups then performed a laboratory mental stress task. Chosen cardiovascular indices were measured before, during, and after these mental stress tasks.

\section{Methods}

\section{Participants}

We firstly established the criterion with which to discriminate between fish-eaters and non-fish eaters. Staple Japanese baked fish preparations usually exceed $70 \mathrm{~g}$, which is significantly greater than the amount of other preparations of fish, such as raw fish, the amount of which is variable and relatively small. We therefore adopted the following simple operational classification to emphasize group differences.

Fish-eating group A total of 12 fish eaters, defined as those who consumed more than $70 \mathrm{~g}$ of baked fish at least 3-4 times/week for at least the last year, participated in the study.

Control group A total of 13 controls, which consumed less than $70 \mathrm{~g}$ of baked fish 1-2 times/week for at least the last year, participated in the study.

The participants were young students, responding to fliers or e-mails distributed by the experimenters. The criteria for inclusion in the study were to be 18 to 30 years of age, having no history of or current cardiovascular disease, and not taking any prescription medication. The participation of women was at random with regard to the menstrual cycle phase.

All the participants received 2,000 Yen (about US\$25) as a reward for their cooperation. After providing a complete description of the study, written informed consent was obtained from all participants. This study was approved by the ethics committee of the National Disaster Medical Center, Tokyo.

\section{Apparatus}

The experiment was conducted in a $3 \times 3-\mathrm{m}$ soundattenuated, temperature-controlled experimental room. A wooden desk and a comfortable chair for participants to sit on were made available in this room. Participants were monitored using a VGA resolution web camera and a condenser microphone (Rhodes, NT2A) placed on the desk. The stress task, described below, was controlled by a computer (Apple, MacOS X 10.4) situated in the control room, and was presented through a LCD monitor (BenQ, FP91G) and small speakers on the desk.

Beat-to-beat blood pressure (BP) was measured noninvasively using a finger-cuff attached to the middle finger of the left hand and connected to a BP monitor (Medisens, MUB101), utilizing the volume-compensation principle $[19,20]$. The measurements obtained using this device were found to be in good agreement with those obtained using a standard oscillometric monitor (GE Healthcare, Dinamap ProCare 100). The electrocardiogram (ECG) was recorded from a pair of disposable electrodes, attaching one electrode to each arm of the participants (that is, standard limb electrocardiogram, lead I), and connecting the electrodes to a bioamplifier (Monte system, ECG100C). The thoracic impedance cardiograms were obtained using 4 circumferential electrodes, which were placed around the participants' neck and chest and connected to an impedance cardiograph (Monte system, NICO100C). The finger photoplethysmogram was recorded using a near-infrared light emitting diode as a light source and a photo diode as a detector, which were placed on the index finger of the left hand and connected to a bioamplifier (Monte system, BIOPAC UIM100C). These signals were amplified using a bioamplifier (Monte system, BIOPAC MP150), sampled at a rate of $1000 \mathrm{~Hz}$ with a resolution of 16 bits and stored digitally in a computer (Apple, iMac).

\section{Laboratory mental stress task}

Baseline (BS) and recovery (R) In both periods, the participants were asked to sit still and observe the blank computer screen.

Mental arithmetic (MA) task The participants were instructed to subtract 13 sequentially from 5000 (to get $4987,4974,4961, \ldots)$ as quickly and accurately as possible [21]. The participants were given voice feedback of "Yes" and "No" for every correct and incorrect answer, respectively. In the latter case, subtraction was continued from the correct answer. The scores achieved by the participants were displayed on the screen, with 2 points added for every correct answer and 1 point subtracted for every incorrect answer. The screen also displayed the target score, which was updated every $20 \mathrm{~s}$, to encourage optimal performance. This score was determined according to the participant's answering speed; that is, the first $20 \mathrm{~s}$ target score was 6 and below. If the participant attained this score, the next target score was 8 added to the present achieved score, but if not, the next target score was 4 added to the present achieved score. The minimum added score was 2 , and the same rule was 
applied until the end of this task. An aversive, glassscratching noise of $68 \mathrm{~dB}(\mathrm{~A})$ was sounded for $1.5 \mathrm{~s}$ every $20 \mathrm{~s}$ if the response was delayed.

\section{Procedure}

The participants were asked in advance to maintain their regular lifestyle, to refrain from any medication before the study, and to avoid consumption of food and caffeine-containing substance, intense physical activity, and smoking for an hour before laboratory testing. After being fitted with instruments for cardiovascular monitoring, they sat on the chair placed before a 17 -inch computer screen in the experimental room during the experiment. A 10-min rest period, with the last $3 \mathrm{~min}$ used as a baseline, was followed by the 5-min mental arithmetic task. Then, a 2-min post-task checklist period was followed by a 9 -min recovery period.

\section{Questionnaires}

Food intake The participants completed a Food Frequency Questionnaire (FFQ) that has been standardized as a dietary assessment tool for Japanese [22,23]. The validity and reliability of this FFQ has been confirmed in terms of accordance with the dietary record and blood sample, and 1-year interval reproducibility $[24,25]$.

Psychometrics The participants completed a Japanese standardized and validated version of the Buss-Perry Aggression Questionnaire (BAQ; [26]), the State-Trait Anxiety Inventory (STAI; [27]), the Short-Form Eysenck Personality Questionnaire-Revised (EPQR-12; [28]), and the Behavioral Inhibition/Activation (Approach) System Scale (BIS/BAS; [29]).

Post-task checklist After they had finished the task, the participants answered 5 simple questions as to their subjective state during the task; attention to the display, unpleasant feelings, effort to cope, task difficulty, and perceived control. All items selected are known to affect cardiovascular reactivity [30-33]. Each item is written in a Likert-type format, with the response made on an 11point response scale, with 0 indicating not at all and 10 indicating extremely high.

\section{Cardiovascular measures and data reduction}

Systolic, mean, and diastolic blood pressure (SBP, MBP, and DBP, respectively) were determined on a beat-bybeat basis. Heart rate (HR) was derived from the R-R intervals of the ECG. Cardiac output (CO) and preejection period (PEP) were determined with a 60-s ensemble-averaging technique [34,35] using the ECG and the impedance cardiogram. Total peripheral resistance (TPR) was calculated as $\mathrm{TPR}=\mathrm{MBP} / \mathrm{CO}$.
Normalized pulse volume (NPV), an index of $\alpha$ adrenalin-mediated sympathetic activity [36], was calculated by dividing the $\mathrm{AC}$ component of the finger photoplethysmogram by its $\mathrm{DC}$ component and then applying a logarithmic transformation to normalize the distribution. Pulse-wave velocity (PWV), an index of arterial stiffness, was calculated as $\mathrm{PWV}=D / \mathrm{PTT}$, where $D$ is the distance between the heart and finger, measured along the body surface, and PTT is the pulse transmission time, calculated as the interval between the pulse wave reaching the finger (DBP point of the BP wave) and the ejection of the blood from the left ventricle $(B$ point of the $\mathrm{d} Z / \mathrm{d} t$ wave). The cardio-finger vascular index (CFVI), which represents arterial stiffness independent of the BP [37], was calculated as CFVI $=[1 /(\mathrm{SBP}$ - DBP $)] \times \ln (\mathrm{SBP} / \mathrm{DBP}) \times \mathrm{PWV}^{2}$. The baroreflex sensitivity (BRS), an index of cardiac vagal activity, was computed using the sequence method [38].

Beat-by-beat SBP, MBP, DBP, HR, and $\ln$ NPV values were averaged over $60 \mathrm{~s}$, and PEP, CO, TPR, PWV, CFVI, and BRS were calculated for the same duration. Subsequently, these values were further averaged to produce BS, MA, and first (0-3 min), second (3-6 min), and third (6-9 min) recovery (R1, R2, and R3, respectively) values, respectively. Reactivity and recovery values were calculated by subtracting BS values from MA values and the mean of these $R$ values; that is, $R 1, R 2$, and $R 3$, respectively.

\section{Statistical analyses}

Physiological data for each group (fish-eating and control) and condition (BS, MA, R1, R2, and R3) were compared statistically by means of a series of separate twoway mixed-design analyses of variance (ANOVAs). The Greenhouse-Geisser correction was applied to the degree of freedom where appropriate. Tukey's Honestly Significant Difference tests (Tukey HSD) for post-hoc comparison were used with a significance level of $5 \%$. Unpaired $t$-tests between groups were also conducted both in reactivity and recovery values. In the case of problems in the measurement of a certain index across a condition, all the measurements of the index in the particular participant were treated as missing data. Other group differences such as diet and psychometrics were compared statistically using unpaired $t$-tests or Chisquare tests with Yates' continuity correction. All analyses were performed using IBM SPSS Statistics 18.0 for MacOS (IBM Inc.).

\section{Results}

\section{Characteristics of the fish-eating and control groups}

The descriptive characteristics of the fish-eating and control groups are summarized in Table 1. The results of statistical tests are also presented in Table 1. 
Table 1 Demographic, anthropometric, dietary, and psychometric characteristics of participants with different fish-eating habits

\begin{tabular}{|c|c|c|c|c|c|}
\hline \multirow[t]{3}{*}{ Characteristics } & \multicolumn{2}{|c|}{ Group } & \multirow[t]{3}{*}{ Statistic } & \multirow[t]{3}{*}{$p$} & \multirow[t]{3}{*}{ ES } \\
\hline & Fish-eating & Control & & & \\
\hline & $M(S D)$ & $M(S D)$ & & & \\
\hline \multicolumn{3}{|l|}{ Demographics } & $x_{1}^{2}$ & & $\varphi$ \\
\hline Gender (M/F) & $2 / 10$ & $2 / 11$ & 0.00 & n.s. & 0.00 \\
\hline Smokers $(\mathrm{Y} / \mathrm{N})$ & $0 / 12$ & $1 / 12$ & 0.00 & n.s. & 0.00 \\
\hline \multicolumn{3}{|l|}{ Anthropometrics } & $t_{23}$ & & $d$ \\
\hline Age (years) & $21.4(3.7)$ & $21.9(3.1)$ & 0.37 & n.s. & 0.15 \\
\hline $\begin{array}{l}\text { Body Mass Index } \\
\left(\mathrm{kg} / \mathrm{m}^{2}\right)\end{array}$ & $21.6(2.7)$ & $20.8(3.1)$ & 0.67 & n.s. & 0.28 \\
\hline \multicolumn{6}{|l|}{ Food Intakes (FFQ) (g/day) } \\
\hline $\begin{array}{l}\text { Eating Fish } \\
\text { (times/week) }\end{array}$ & $3.8(0.8)$ & $1.0(0.6)$ & 9.92 & $<.001$ & 4.14 \\
\hline Fish and Seafood & $91.7(34.7)$ & $48.2(32.7)$ & 3.22 & $<.004$ & 1.34 \\
\hline Mushroom & $5.4(4.7)$ & $5.9(5.4)$ & 0.25 & n.s. & 0.10 \\
\hline Algae & $7.5(3.7)$ & $3.9(3.7)$ & 2.40 & $<.03$ & 1.00 \\
\hline Alcohol & $39.1(101.1)$ & $60.8(195.7)$ & $1.09^{\mathrm{a}}$ & n.s. & 0.44 \\
\hline Fruits & $111.9(88.9)$ & $44.4(52.7)$ & 2.33 & $<.03$ & 0.97 \\
\hline Vegetables & $367.8(251.0)$ & $230.7(120.7)$ & $1.72^{b}$ & $<.10$ & 0.74 \\
\hline $\begin{array}{l}\text { Green and Yellow } \\
\text { Vegetables }\end{array}$ & $144.6(84.0)$ & $93.8(70.2)$ & 1.65 & n.s. & 0.69 \\
\hline Cereal & $256.2(88.9)$ & $203.3(92.7)$ & 1.45 & n.s. & 0.61 \\
\hline $\begin{array}{l}\text { Processed Tubers } \\
\text { and Roots }\end{array}$ & $57.8(58.1)$ & $50.6(48.8)$ & 0.34 & n.s. & 0.14 \\
\hline Pulse Products & $57.9(49.6)$ & $56.3(59.5)$ & 0.07 & n.s. & 0.03 \\
\hline Meat & $107.8(60.2)$ & $103.0(71.2)$ & 0.18 & n.s. & 0.08 \\
\hline Egg & $48.7(34.4)$ & $29.1(17.5)$ & 1.81 & $<.09$ & 0.75 \\
\hline Dairy Product & $91.7(152.1)$ & $146.5(132.7)$ & 0.96 & n.s. & 0.40 \\
\hline \multicolumn{6}{|l|}{ Psychometrics } \\
\hline Aggression (BAQ) & $56.3(7.3)$ & $50.9(10.0)$ & 1.00 & n.s. & 0.63 \\
\hline $\begin{array}{l}\text { Trait Anxiety } \\
\text { (STAl A-trait) }\end{array}$ & $35.2(12.1)$ & $40.5(9.3)$ & 1.23 & n.s. & 0.51 \\
\hline Neuroticism (EPQR-12) & $5.0(2.8)$ & $7.2(2.4)$ & 2.07 & $<.06$ & 0.86 \\
\hline $\begin{array}{l}\text { Behavioral Inhibition } \\
\text { (BIS) }\end{array}$ & $39.0(6.4)$ & $38.8(10.0)$ & 0.07 & n.s. & 0.03 \\
\hline $\begin{array}{l}\text { Behavioral Activation } \\
\text { (BAS) }\end{array}$ & $45.0(8.7)$ & $38.6(5.6)$ & 2.20 & $<.04$ & 0.92 \\
\hline
\end{tabular}

Note. $X^{2}=$ Yates corrected Chi-square.

${ }^{\mathrm{a}} d f=14 ;{ }^{\mathrm{b}} d f=15$.

\section{Post-task checklist}

Subjective ratings for the MA task are summarized in Table 2. The results of statistical tests are also presented in Table 2.

\section{Cardiovascular measures}

Cardiovascular responses are shown in Figure 1. The results of a series of Group (fish-eating and control) $\times$
Table 2 Subjective rating to the mental arithmetic task

\begin{tabular}{|c|c|c|c|c|c|}
\hline \multirow[t]{3}{*}{ Post-Task Checklist } & \multicolumn{2}{|c|}{ Group } & \multirow[t]{3}{*}{$t_{23}$} & \multirow[t]{3}{*}{$p$} & \multirow[t]{3}{*}{$d$} \\
\hline & Fish-eating & Control & & & \\
\hline & $M(S D)$ & $\overline{M(S D)}$ & & & \\
\hline \multicolumn{6}{|l|}{ Items } \\
\hline Attention to the Display & $3.8(1.7)$ & $5.5(3.3)$ & $1.73^{a}$ & n.s. & 0.70 \\
\hline Unpleasant Feelings & $6.5(2.7)$ & $6.7(2.3)$ & 0.19 & n.s. & 0.08 \\
\hline Effort to Cope & $7.8(1.9)$ & $8.3(1.3)$ & 0.74 & n.s. & 0.31 \\
\hline Task Difficulty & $8.0(1.7)$ & $8.7(1.8)$ & 0.99 & n.s. & 0.41 \\
\hline Perceived Control & $3.8(1.9)$ & $3.2(2.5)$ & 0.76 & n.s. & 0.32 \\
\hline
\end{tabular}

Condition (BS, MA, R1, R2, and R3) ANOVAs and of their post-hoc tests are summarized in Table 3 . We also conducted ANOVAs using BS values as covariate, but results hardly changed. Therefore, we only represent the results of simple ANOVAs.

The reactivity and recovery values together with the results of unpaired $t$-tests are presented in Table 4.

\section{Discussion}

In this laboratory study, the fish-eating group showed distinct and unique cardiovascular response patterns before, during, and in recovery from MA, as compared to the control group. Specifically, lower BP, HR, PWV, and CFVI, higher BRS and PEP, and faster SBP and MBP recovery were observed in the fish-eating group. Such patterns clearly represent healthy cardiovascular responses and arterial elasticity of the fish-eating group, and this is highly consistent with that observed in previous studies. For example, as mentioned above, one study [5] that examined elderly people revealed that fish-eaters had lower HR and BP. Although the results in our study did not reach a statistically significant level, their study detected lower TPR and higher SV, and comparable CO. Similarly, our finding of lower PWV and CFVI, reflecting arterial stiffness independent of BP, corresponds well with a study [39] that examined atherosclerosis of middle-aged Japanese, Japanese-American, and White men in relation to fish consumption. Frequent fish consumption is highly likely to promote cardiovascular health in a younger population, as it appears to in the older populations.

Faster SBP and MBP recovery following MA was observed in the fish-eating group. On the other hand, no reduced reactivity to MA was detected in any indices, even though some raw values during MA in the fisheating group were different from those in the control group. As clearly seen in Figure 1, the slopes of the lines through points $\mathrm{BS}$ and $\mathrm{MA}$ in two groups were the same, thus group differences in reactivity, defined as changes from baseline to the task [40], were not 

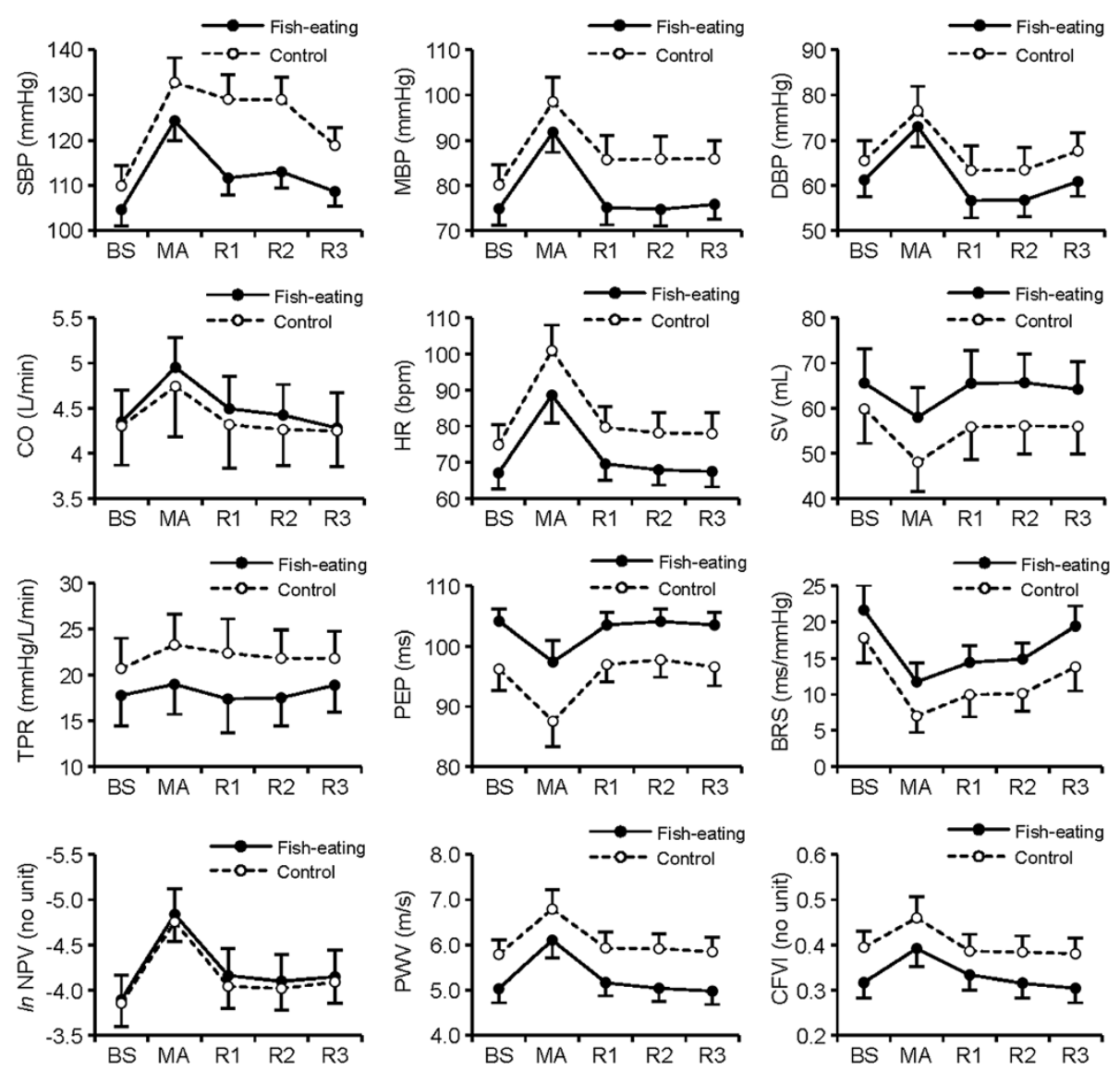

Figure 1 Cardiovascular responses during baseline, mental stress, and recovery. Means (S.E.M.) of systolic, mean, and diastolic blood pressure (SBP, MBP, and DBP, respectively), cardiac output (CO), heart rate (HR), stroke volume (SV), total peripheral resistance (TPR), pre-ejection period (PEP), baroreflex sensitivity (BRS), In normalized pulse volume (In NPV), pulse wave velocity (PWV), and cardio-finger vascular index (CFVI) during baseline (BS), mental arithmetic (MA), and the $1^{\text {st }}, 2^{\text {nd }}$, and $3^{\text {rd }}$ recovery (R1, R2, and $R 3$, respectively).

observed. In relation to these unique response patterns, some researchers have proposed an interesting view that what is causally related to atherosclerosis are higher or lower raw values in themselves, rather than higher reactivity to the stress [41,42]. As an example, $70 \mathrm{bpm} \mathrm{HR}$ during baseline increased to $100 \mathrm{bpm}$ during stress and $80 \mathrm{bpm}$ HR during baseline increased to $110 \mathrm{bpm}$ during stress are comparable in terms of reactivity, but the latter would be worse for future cardiovascular health. According to this view, it follows that the effect of frequent fish consumption on cardiovascular health should be mediated by modulations in raw values, rather than reduced reactivity. Further studies on this aspect would be needed.

We measured subjective ratings during MA using a post-task checklist, but no group differences were observed. Thus, these inner states do not noticeably affect cardiovascular measures in this study. However, these results do not necessarily rule out the possibility that relatively small sample size simply made it difficult to reach a statistically significant level. Thus, in future research, adopting a more detailed or standardized subjective ratings questionnaire such as Attention-Affect Check List (AACL; [43]), or manipulating these variables in a positive manner such as by using previously established paradigm [44], will be needed.

We also asked participants to answer psychometrics, yet the scores for the behavioral approach (activation) system (BAS) were higher in the fish-eating group. Although higher BAS score have already been shown to be related to higher HR reactivity [45], our cardiovascular data did not show such a tendency. This is possibly due to the characteristic feature of our MA task, in that there was no monetary bonus, but instead a glassscratching noise punishment, and both groups of participants felt higher task difficulty and unpleasant feelings and lower perceived control, and as such, the BAS system was not activated.

A group difference in fish-eating habit was a salient feature, but such a dietary pattern was accompanied by modulation in other food categories, including a higher intake amount of fruits, algae, and vegetables. Besides 
Table 3 Summary of a series of separate Analyses of Variances (ANOVAs)

\begin{tabular}{|c|c|c|c|c|c|c|c|c|c|c|c|c|}
\hline \multirow[t]{3}{*}{ Cardiovascular Measures } & \multicolumn{7}{|c|}{ Main Effect } & \multirow{2}{*}{\multicolumn{4}{|c|}{$\begin{array}{c}\text { Interaction } \\
\text { Group } \times \text { Period }\end{array}$}} & \multirow{3}{*}{$\begin{array}{c}\text { Summary of ANOVA and } \\
\text { Post-hoc Test }\end{array}$} \\
\hline & \multicolumn{3}{|c|}{ Group } & \multicolumn{4}{|c|}{ Period } & & & & & \\
\hline & $F_{1,23}$ & $p$ & $\eta_{p}^{2}$ & $F_{4,92}$ & $p$ & $\epsilon$ & $\eta_{p}^{2}$ & $F_{4,92}$ & $p$ & $\epsilon$ & $\eta_{p}^{2}$ & \\
\hline \multicolumn{13}{|l|}{ Hemodynamics } \\
\hline SBP & 6.15 & $<.03$ & .21 & 30.84 & $<.001$ & .79 & .57 & 3.10 & $<0.05$ & .79 & .12 & FE $<$ Cont on R1, R2, and R3 \\
\hline $\mathrm{MBP}$ & 5.47 & $<.03$ & .19 & 56.56 & $<.001$ & .76 & .71 & 1.94 & n.s. & .76 & .08 & $\mathrm{FE}<$ Cont; $\mathrm{BS}, \mathrm{R} 2, \mathrm{R} 1, \mathrm{R} 3<\mathrm{MA}$ \\
\hline DBP & 4.04 & $<.06$ & .15 & 78.19 & $<.001$ & .62 & .77 & 1.37 & n.s. & 62 & .06 & $\mathrm{FE}<$ Cont; R1, $\mathrm{R} 2<\mathrm{BS}, \mathrm{R} 3<\mathrm{MA}$ \\
\hline \multicolumn{13}{|l|}{ Cardiac } \\
\hline $\mathrm{CO}$ & 0.08 & n.s. & .00 & 5.84 & $<.006$ & .49 & .20 & 0.17 & n.s. & .49 & .01 & $\mathrm{R} 3, \mathrm{BS}, \mathrm{R} 2, \mathrm{R} 1<\mathrm{MA}$ \\
\hline$H R$ & 5.55 & $<.03$ & .19 & 65.52 & $<.001$ & .32 & .74 & 0.47 & n.s. & .32 & .02 & $\mathrm{FE}<$ Cont; $\mathrm{BS}, \mathrm{R} 3, \mathrm{R} 2, \mathrm{R} 1<\mathrm{MA}$ \\
\hline SV & 1.68 & n.s. & .07 & 10.66 & $<.001$ & .70 & .32 & 0.58 & n.s. & .70 & .02 & $B S, R 2, R 1, R 3>M A$ \\
\hline \multicolumn{13}{|l|}{ Vascular } \\
\hline TPR & 2.52 & n.s. & .10 & 2.28 & n.s. & .74 & .09 & 0.90 & n.s. & .74 & .04 & \\
\hline
\end{tabular}

Autonomic Activities

Sympathetic

$\begin{array}{lcccccccccccc}\text { PEP } & 10.32 & <.004 & .31 & 25.75 & <.001 & .42 & .53 & 1.10 & \text { n.s. } & .42 & .05 & \text { FE }>\text { Cont; R2, R1, BS, R3 > MA } \\ \text { In NPV } & 0.10^{a} & \text { n.s. } & .00 & 46.5^{\mathrm{b}} & <.001 & .68 & .68 & 0.08^{\mathrm{b}} & \text { n.s. } & .68 & .00 & \text { BS, R2 }>\text { R2, R1, R3 > MA }\end{array}$

Vagal

$$
\text { BRS }
$$$$
4.39^{c}<.05 \quad .17 \quad 26.29^{d}
$$$$
<.001 \quad .63 \quad .56 \quad 0.16^{d} \quad \text { n.s. }
$$

$\mathrm{FE}>$ Cont; $\mathrm{BS}, \mathrm{R} 3>\mathrm{R} 2, \mathrm{R} 1>\mathrm{R} 1, \mathrm{MA}$

Arterial Stiffness

\begin{tabular}{lcccccccccccc} 
PWV & 10.33 & $<.004$ & .31 & 73.73 & $<.001$ & .34 & .76 & 0.56 & n.s. & .34 & .02 & FE $<$ Cont; BS, R3, R2, R1 < MA \\
CFVI & 6.09 & $<.03$ & .21 & 28.27 & $<.001$ & .47 & .55 & 0.61 & n.s. & .47 & .03 & FE $<$ Cont; R3, R2, BS, R1 < MA \\
\hline
\end{tabular}

Note. ${ }^{\mathrm{a}} d f=1,22 ;{ }^{\mathrm{b}} d f=4,88 ;{ }^{\mathrm{c}} d f=1,21 ;{ }^{\mathrm{d}} d f=4,84$.

Period(s) separated by comma and printed both sides of inequality sign are not significantly different at $p<.05$.

$F E=$ fish-eating, Cont $=$ control.

$B S=$ baseline, $M A=$ mental arithmetic, $R 1=1^{\text {st }}$ recovery, $R 2=2^{\text {nd }}$ recovery, and $R 3=3^{\text {rd }}$ recovery.

$S B P=$ systolic blood pressure, $M B P=$ mean blood pressure, $D B P=$ diastolic blood pressure, $C O=$ cardiac output, $H R=$ heart rate, $S V=$ stroke volume, $T P R=$ total peripheral resistance, $P E P=$ pre-ejection period, $N P V=$ normalized pulse volume, $B R S=$ baroreflex sensitivity, $P W V=$ pulse wave velocity, and $C F V I=$ cardio-finger vascular index.

algae, that was only recorded at very low intakes and is similar to fish, being marine-derived, fruits and vegetables are known to be good for cardiovascular health [46], thus, in theory, their possible effects in our present study can not be ignored. However, at present, the relationship between consumption of fruits and vegetables and cardiovascular responses during mental stress is not established. In contrast, the cardiovascular response patterns observed in our fish-eating group were in quite good agreement not only with those observed in previous fish-eater studies, as mentioned above, but also with those obtained from studies supplementing fish oil to participants $[47,48]$, and it is very difficult to explain such distinct and unique patterns from the viewpoint of other factors. Thus, at least as with respect to cardiovascular measures, it is likely that the group differences were mainly due to the difference of fish-eating habit.

In relation to the above, fish-eating is considered to be a healthy diet in Western countries. In this study, we simply asked the participants after finishing the experiment why they ate fish. Their answers were either that "I like fish" or "it is prepared in my house", or both of these. These answers clearly show the attitude of Japanese to eating fish; that is, the majority of Japanese do not regard fish as a healthy diet, but as a delicious and/ or traditional one. Thus, at least with regard to our participants, it is very unlikely that a high health attitude promotes other healthy behaviors, such as exercise, which in turn affect cardiovascular measures.

There are some limitations in this study. Firstly, although the differences seen in our cardiovascular data appeared to be statistically significant, the relatively small sample size makes the use of covariate analysis to adjust for possible confounding factors, such as personality traits and dietary habits other than fish, rather difficult. Thus, future studies, in which larger sample sizes are recruited, are needed, though young people are rarely expected to be classified into a fish-eating group. Secondly, we only used the MA task, but there are other tasks that evoke different hemodynamic reaction patterns. It could be fruitful to use a cold pressor test, which can provoke vascular responses, or a real-life 
Table 4 Cardiovascular reactivity and recovery values

\begin{tabular}{|c|c|c|c|c|c|c|c|c|c|c|}
\hline \multirow[t]{4}{*}{ Cardiovascular Measures } & \multicolumn{5}{|c|}{ Reactivity } & \multicolumn{5}{|c|}{ Recovery } \\
\hline & \multicolumn{2}{|c|}{ Group } & \multirow[t]{3}{*}{$t_{23}$} & \multirow[t]{3}{*}{$p$} & \multirow[t]{3}{*}{$d$} & \multicolumn{2}{|c|}{ Group } & \multirow[t]{3}{*}{$t_{23}$} & \multirow[t]{3}{*}{$p$} & \multirow[t]{3}{*}{$d$} \\
\hline & Fish-eating & Control & & & & Fish-eating & Control & & & \\
\hline & $M(S D)$ & $M(S D)$ & & & & $\overline{M(S D)}$ & $M(S D)$ & & & \\
\hline \multicolumn{11}{|l|}{ Hemodynamics } \\
\hline $\mathrm{SBP}, \mathrm{mmHg}$ & $19.7(7.7)$ & $22.8(12.2)$ & 0.77 & n.s. & 0.31 & $6.5(7.8)$ & $15.7(11.5)$ & 2.32 & $<.03$ & 0.95 \\
\hline $\mathrm{MBP}, \mathrm{mmHg}$ & $16.9(5.8)$ & $18.4(8.6)$ & 0.49 & n.s. & 0.20 & $0.4(4.4)$ & $5.7(5.9)$ & 2.53 & $<.02$ & 1.02 \\
\hline $\mathrm{DBP}, \mathrm{mmHg}$ & $11.7(4.5)$ & $11.0(4.7)$ & 0.40 & n.s. & 0.16 & $-3.2(4.1)$ & $-0.7(5.0)$ & 1.36 & n.s. & 0.55 \\
\hline \multicolumn{11}{|l|}{ Cardiac } \\
\hline $\mathrm{CO}, \mathrm{L} / \mathrm{min}$ & $0.60(0.66)$ & $0.44(1.20)$ & 0.42 & n.s. & 0.17 & $0.05(0.46)$ & $-0.03(0.41)$ & 0.44 & n.s. & 0.18 \\
\hline $\mathrm{HR}$, bpm & $21.4(15.1)$ & $26.1(12.1)$ & 0.87 & n.s. & 0.35 & $1.3(3.1)$ & $3.8(5.1)$ & 1.47 & n.s. & 0.61 \\
\hline $\mathrm{SV}, \mathrm{mL}$ & $-7.6(8.5)$ & $-11.7(13.0)$ & $0.94^{\mathrm{a}}$ & n.s. & 0.38 & $-0.5(7.3)$ & $-3.9(6.3)$ & 1.25 & n.s. & 0.50 \\
\hline \multicolumn{11}{|l|}{ Vascular } \\
\hline $\mathrm{TPR}, \mathrm{mmHg} / \mathrm{L} / \mathrm{min}$ & $1.2(2.5)$ & $2.6(4.4)$ & 0.93 & n.s. & 0.39 & $0.2(2.2)$ & $1.3(2.1)$ & 1.33 & n.s. & 0.53 \\
\hline \multicolumn{11}{|l|}{ Autonomic Activities } \\
\hline \multicolumn{11}{|l|}{ Sympathetic } \\
\hline PEP, ms & $-6.7(6.7)$ & $-8.7(7.9)$ & 0.66 & n.s. & 0.27 & $-0.4(2.0)$ & $0.9(4.4)$ & 0.97 & n.s. & 0.41 \\
\hline In NPV & $-0.94(0.31)$ & $-0.90(0.54)$ & $0.24^{b}$ & n.s. & 0.10 & $-0.24(0.36)$ & $-0.20(0.30)$ & $0.32^{b}$ & n.s. & 0.13 \\
\hline \multicolumn{11}{|l|}{ Vagal } \\
\hline $\mathrm{BRS}, \mathrm{ms} / \mathrm{mmHg}$ & $-9.9(8.4)$ & $-10.8(7.1)$ & $0.28^{c}$ & n.s. & 0.12 & $-5.4(5.8)$ & $-6.5(4.0)$ & $0.53^{c}$ & n.s. & 0.23 \\
\hline \multicolumn{11}{|l|}{ Arterial Stiffness } \\
\hline $\mathrm{PW}, \mathrm{m} / \mathrm{s}$ & $1.06(0.57)$ & $1.00(0.46)$ & 0.30 & n.s. & 0.12 & $0.03(0.17)$ & $0.11(0.20)$ & 1.08 & n.s. & 0.44 \\
\hline CFVI & $0.08(0.07)$ & $0.07(0.06)$ & 0.39 & n.s. & 0.16 & $0.00(0.03)$ & $-0.01(0.04)$ & 0.94 & n.s. & 0.38 \\
\hline
\end{tabular}

Note. ${ }^{\mathrm{a}} d f=20 ;^{\mathrm{b}} d f=22 ;{ }^{\mathrm{c}} d f=21$.

$S B P=$ systolic blood pressure, $M B P=$ mean blood pressure, $D B P=$ diastolic blood pressure, $C O=$ cardiac output, $H R=$ heart rate, $S V=\mathrm{stroke}$ volume, $T P R=$ total peripheral resistance, $P E P=$ pre-ejection period, $N P V=$ normalized pulse volume, $B R S=$ baroreflex sensitivity, $P W V=$ pulse wave velocity, and $C F V I=$ cardio-finger vascular index.

competitive situation as an intense stressor [49]. Thirdly, we did not measure cardiovascular indices during the 2min checklist period. Although we have assumed that the measured variables would gradually recover from the task, we cannot exclude the possibility that a relevant acute event might have occurred. So, in future studies, procedures that enable us to record both physiological and psychological measures simultaneously should be adopted. Despite these limitations, our study revealed that fish-eaters show a more favorable cardiovascular response to a mental stress task and better arterial elasticity than non-fish eaters. Taken together with the slowly developing nature of cardiovascular disease, the long succession of such psychophysiological modulation might suggest a potential underlying mechanism by which frequent fish consumption protects against CHD.

\section{Abbreviations}

CHD: Coronary heart disease; DHA: Docosahexaenoic acid;

EPA: Eicosapentaenoic acid; RCT: Randomized control trial; FFQ: Food Frequency Questionnaire; BAQ: Buss-Perry Aggression Questionnaire;

STAl: State-Trait Anxiety Inventory; EPQR-12: Short-Form Eysenck Personality Questionnaire-Revised; BIS: Behavioral Inhibition System; BAS: Behavioral Activation (Approach) System; BS: Baseline; MA: Mental arithmetic; R1: $1^{\text {st }}$ recovery; R2: $2^{\text {nd }}$ recovery; $\mathrm{R} 3: 3^{\text {rd }}$ recovery; SBP: Systolic blood pressure; MBP: Mean blood pressure; DBP: Diastolic blood pressure; CO: Cardiac output; HR: Heart rate; SV: Stroke volume; TPR: Total peripheral resistance; PEP: Pre-ejection period; BRS: Baroreflex sensitivity; NPV: Normalized pulse volume; PTT: Pulse transmission time; PWV: Pulse wave velocity; CFVI: Cardiofinger vascular index

\section{Competing interests}

The authors declare that they have no competing interests.

\section{Acknowledgements}

The study was supported by a Grand-in-Aid for Young Scientists (B) from the Japan Society for the Promotion of Science (22700707) and Japan Science and Technology Agency - CREST only for the promotion of science.

\section{Author details}

1Department of Adult Mental Health, National Institute of Mental Health, National Center of Neurology and Psychiatry, 4-1-1 Ogawa-Higashi, Kodaira, Tokyo 187-8553, Japan. ${ }^{2}$ Graduate School of Natural Science and Technology, Kanazawa University, Kakuma-machi, Kanazawa, Ishikawa 920-1192, Japan.

${ }^{3}$ Clinical Psychology Center, Musashino University, 3-40-10 Sekimae,

Musashino, Tokyo 180-0023, Japan. ${ }^{4}$ Department of Automatic Measurement and Control, Harbin Institute of Technology, No.92 West Da-Zhi Street, Harbin, Heilongjiang 150001, China. ${ }^{5}$ Department of Psychiatry and Clinical Research Institute, National Disaster Medical Center, 3256 Midori-cho, Tachikawa, Tokyo 190-0014, Japan. ${ }^{6}$ CREST, Japan Science and Technology Agency, 3256 Midori-cho, Tachikawa, Tokyo 190-0014, Japan. ${ }^{7}$ Translational Medical Center, National Center of Neurology and Psychiatry, 4-1-1 OgawaHigashi, Kodaira, Tokyo 187-8551, Japan. 


\section{Authors' contributions}

KM conceived and designed the study, performed the experiment and the analysis and drafted the manuscript. TY helped to conceive and design the study, performed the analysis, and helped to draft the manuscript. HN performed the experiment and the analysis. PR revised the manuscript critically. YM revised the manuscript critically and gave final approval of the version to be published. All authors read and approved the final manuscript.

\section{Authors' information}

Kenta Matsumura and Takehiro Yamakoshi are now at School of Mechanical Engineering, College of Science and Technology, Kanazawa University, Japan. Hiroko Noguchi is now at Translational Medical Center, National Center of Neurology and Psychiatry, Japan.

Received: 6 January 2012 Accepted: 13 June 2012

Published: 13 June 2012

\section{References}

1. He K, Song Y, Daviglus ML, Liu K, Van Horn L, Dyer AR, Greenland P: Accumulated evidence on fish consumption and coronary heart disease mortality: a meta-analysis of cohort studies. Circulation 2004, 109:2705-2711.

2. Iso H, Kobayashi M, Ishihara J, Sasaki S, Okada K, Kita Y, Kokubo Y, Tsugane S: Intake of fish and $\mathrm{n} 3$ fatty acids and risk of coronary heart disease among Japanese: the Japan Public Health Center-Based (JPHC) Study Cohort I. Circulation 2006, 113:195-202.

3. Kris-Etherton PM, Harris WS, Appel L: Fish consumption, fish oil, omega-3 fatty acids, and cardiovascular disease. Circulation 2002, 106:2747-2757.

4. Mozaffarian D, Rimm EB: Fish intake, contaminants, and human health: evaluating the risks and the benefits. JAMA 2006, 296:1885-1899.

5. Mozaffarian D, Gottdiener JS, Siscovick DS: Intake of tuna or other broiled or baked fish versus fried fish and cardiac structure, function, and hemodynamics. Am J Cardiol 2006, 97:216-222.

6. Treiber FA, Kamarck T, Schneiderman N, Sheffield D, Kapuku G, Taylor T: Cardiovascular reactivity and development of preclinical and clinical disease states. Psychosom Med 2003, 65:46-62.

7. Schwartz AR, Gerin W, Davidson KW, Pickering TG, Brosschot JF, Thayer JF, Christenfeld N, Linden W: Toward a causal model of cardiovascular responses to stress and the development of cardiovascular disease. Psychosom Med 2003, 65:22-35.

8. Krantz DS, Manuck SB: Acute psychophysiologic reactivity and risk of cardiovascular disease: a review and methodologic critique. Psychol Bull 1984, 96:435-464.

9. Tuomisto MT, Majahalme S, Kahonen M, Fredrikson M, Turjanmaa V: Psychological stress tasks in the prediction of blood pressure level and need for antihypertensive medication: 9-12 years of follow-up. Health Psychol 2005, 24:77-87.

10. Chida Y, Steptoe A: Greater cardiovascular responses to laboratory mental stress are associated with poor subsequent cardiovascular risk status: a meta-analysis of prospective evidence. Hypertension 2010 55:1026-1032.

11. Kasprowicz AL, Manuck SB, Malkoff SB, Krantz DS: Individual-differences in behaviorally evoked cardiovascular-response - temporal stability and hemodynamic patterning. Psychophysiology 1990, 27:605-619.

12. Sherwood A, Girdler SS, Bragdon EE, West SG, Brownley KA, Hinderliter AL, Light KC: Ten-year stability of cardiovascular responses to laboratory stressors. Psychophysiology 1997, 34:185-191.

13. Delarue J, Matzinger O, Binnert C, Schneiter P, Chiolero R, Tappy L: Fish oil prevents the adrenal activation elicited by mental stress in healthy men. Diabetes Metab 2003, 29:289-295.

14. Spence JD, Thornton T, Muir AD, Westcott ND: The effect of flax seed cultivars with differing content of alpha-linolenic acid and lignans on responses to mental stress. J Am Coll Nutr 2003, 22:494-501.

15. Ginty AT, Conklin SM: Preliminary evidence that acute long-chain omega3 supplementation reduces cardiovascular reactivity to mental stress: a randomized and placebo controlled trial. Biol Psychol 2012, 89:269-272.

16. Mills DE, Prkachin KM, Harvey KA, Ward RP: Dietary fatty acid supplementation alters stress reactivity and performance in man. $J$ Hum Hypertens 1989, 3:111-116.

17. Lavie CJ, Milani RV, Mehra MR, Ventura HO: Omega-3 polyunsaturated fatty acids and cardiovascular diseases. J Am Coll Cardiol 2009, 54:585-594.
18. Mozaffarian D, Geelen A, Brouwer IA, Geleijnse JM, Zock PL, Katan MB: Effect of fish oil on heart rate in humans: a meta-analysis of randomized controlled trials. Circulation 2005, 112:1945-1952.

19. Yamakoshi K, Oberg PA, Togawa T, Spelman FA: Non-Invasive Cardiovascular Hemodynamic Measurements. In Sensors in Medicine and Health Care: Sensors Applications. Volume 3. Weinheim: Wiley-VCH Verlag; 2004:107-160. doi:10.1002/3527601414.ch5.

20. Yamakoshi K, Shimazu H, Togawa T: Indirect measurement of instantaneous arterial blood pressure in the human finger by the vascular unloading technique. IEEE Trans Biomed Eng 1980, 27:150-155.

21. Allen MT, Obrist PA, Sherwood A, Crowell MD: Evaluation of myocardial and peripheral vascular responses during reaction time, mental arithmetic, and cold pressor tasks. Psychophysiology 1987, 24:648-656.

22. Sasaki S, Kobayashi M, Tsugane S: Validity of a self-administered food frequency questionnaire used in the 5-year follow-up survey of the JPHC Study Cohort I: comparison with dietary records for food groups. J Epidemiol 2003, 13:S57-S63.

23. Tsugane S, Kobayashi M, Sasaki S: Validity of the self-administered food frequency questionnaire used in the 5-year follow-up survey of the JPHC Study Cohort I: comparison with dietary records for main nutrients. $J$ Epidemiol 2003, 13:S51-S56.

24. Ishihara J, Sobue T, Yamamoto S, Yoshimi I, Sasaki S, Kobayashi M, Takahashi $T$, litoi Y, Akabane M, Tsugane S: Validity and reproducibility of a selfadministered food frequency questionnaire in the JPHC Study Cohort II: study design, participant profile and results in comparison with Cohort I. J Epidemiol 2003, 13:S134-S147.

25. Tsugane S, Sasaki S, Kobayashi M, Tsubono Y, Akabane M: Validity and reproducibility of the self-administered food frequency questionnaire in the JPHC Study Cohort I: study design, conduct and participant profiles. J Epidemiol 2003, 13:S2-S12.

26. Ando A, Soga S, Yamasaki K, Shimai S, Shimada H, Utsuki N, Oashi O, Sakai A: Development of the Japanese version of the Buss-Perry Aggression Questionnaire (BAQ). Shinrigaku Kenkyu 1999, 70:384-392.

27. Kishimoto Y, Terasaki M: Development of The Japanese Version of StateTrait Anxiety Inventory (STAI). The Research bulletin of the Faculty of General Education 1986, 17:1-14.

28. Hosokawa T, Ohyama M: Reliability and Validity of a Japanese Version of the Short-Form Eysenck Personality Questionnarie-Revised. PsycholRep 1993, 72:823-832.

29. Yasuda A, Sato A: Development of the behavioral inhibition system/ behavioral approach system scales. Shinrigaku Kenkyu 2002, 73:234-242.

30. Gerin W, Pieper C, Marchese L, Pickering TG: The multi-dimensional nature of active coping: differential effects of effort and enhanced control on cardiovascular reactivity. Psychosom Med 1992, 54:707-719.

31. Sawada Y, Nagano Y, Tanaka G: Mirror tracing and the provocation of vascular-dominant reaction pattern through heightened attention. J Psychophysiol 2002, 16:201-210

32. Light KC, Obrist PA: Task difficulty, heart rate reactivity, and cardiovascular responses to an appetitive reaction time task. Psychophysiology 1983, 20:301-312.

33. Matsumura K, Sawada Y: Cardiovascular responses during two kinds of mental arithmetic tasks. Shinrigaku Kenkyu 2009, 79:473-480.

34. Lozano DL, Norman G, Knox D, Wood BL, Miller BD, Emery CF, Berntson GG: Where to B in dZ/dt. Psychophysiology 2007, 44:113-119.

35. Sherwood A, Allen MT, Fahrenberg J, Kelsey RM, Lovallo WR, van Doornen L: Methodological guidelines for impedance cardiography. Psychophysiology 1990, 27:1-23.

36. Sawada Y, Tanaka G, Yamakoshi K: Normalized pulse volume (NPV) derived photo-plethysmographically as a more valid measure of the finger vascular tone. Int J Psychophysiol 2001, 41:1-10.

37. Shirai K, Utino J, Otsuka K, Takata M: A novel blood pressure-independent arterial wall stiffness parameter; cardio-ankle vascular index (CAVI). J Atheroscler Thromb 2006, 13:101-107.

38. Steptoe A, Sawada Y: Assessment of baroreceptor reflex function during mental stress and relaxation. Psychophysiology 1989, 26:140-147.

39. Sekikawa A, Curb JD, Ueshima H, El-Saed A, Kadowaki T, Abbott RD, Evans RW, Rodriguez BL, Okamura T, Sutton-Tyrrell K, et al: Marine-derived n-3 fatty acids and atherosclerosis in Japanese, Japanese-American, and white men: a cross-sectional study. J Am Coll Cardiol 2008, 52:417-424.

40. Matsumura K, Yamakoshi T, Rolfe P: Love styles and cardiovascular responder types. Int J Psychol Stud 2011, 3:21-28. 
41. Sharpley CF: Psychosocial stress-induced heart rate reactivity and atherogenesis: cause or correlation? J Behav Med 1998, 21:411-432

42. Beere PA, Glagov S, Zarins CK: Retarding effect of lowered heart rate on coronary atherosclerosis. Science 1984, 226:180-182.

43. Sawada Y, Tanaka G: Attention-Affect Check List: A self-report measure of acute mental stress. Jpn Psychol Res 2004, 46:121-126.

44. Stewart CC, Wright RA, Hui SK, Simmons A: Outcome expectancy as a moderator of mental fatigue influence on cardiovascular response. Psychophysiology 2009, 46:1141-1149.

45. Heponiemi T, Keltikangas-Jarvinen L, Kettunen J, Puttonen S, Ravaja N: BISBAS sensitivity and cardiac autonomic stress profiles. Psychophysiology 2004, 41:37-45.

46. Ness AR, Powles JW: Fruit and vegetables, and cardiovascular disease: a review. Int J Epidemiol 1997, 26:1-13.

47. Hjerkinn EM, Abdelnoor M, Breivik L, Bergengen L, Ellingsen I, Seljeflot L, Aase O, Ole Klemsdal T, Hjermann I, Arnesen H: Effect of diet or very long chain omega-3 fatty acids on progression of atherosclerosis, evaluated by carotid plaques, intima-media thickness and by pulse wave propagation in elderly men with hypercholesterolaemia. Eur J Cardiovasc Prev Rehabil 2006, 13:325-333.

48. Mori TA, Bao DQ, Burke V, Puddey IB, Beilin LJ: Docosahexaenoic acid but not eicosapentaenoic acid lowers ambulatory blood pressure and heart rate in humans. Hypertension 1999, 34:253-260.

49. Matsumura K, Yamakoshi T, Yamakoshi Y, Rolfe P: The effect of competition on heart rate during kart driving: A field study. BMC Res Notes 2011, 4:342.

doi:10.1186/1756-0500-5-288

Cite this article as: Matsumura et al:: Fish consumption and

cardiovascular response during mental stress. BMC Research Notes 2012 5:288.

\section{Submit your next manuscript to BioMed Central and take full advantage of:}

- Convenient online submission

- Thorough peer review

- No space constraints or color figure charges

- Immediate publication on acceptance

- Inclusion in PubMed, CAS, Scopus and Google Scholar

- Research which is freely available for redistribution 